\title{
Musik Rilisan Fisik Di Era Digital: Musik Indie Dan Konsumsi Rilisan Musik Fisik
}

\author{
Riomanadona M Putra, Irwansyah \\ Universitas Indonesia \\ J1. Margonda Raya, Pondok Cina Depok, Jawa Barat \\ riomanadona@gmail.com,dr.irwansyah.ma@gmail.com
}

Masuk tanggal : 27-05-2019, revisi tanggal : 29-07-2019, diterima untuk diterbitkan tanggal : 13-09-2019

\begin{abstract}
The release of physical music will never be extinct, as is technology disrupting audio technology. This article provides an explanation of physical music releases in the digital era, where vinyl records, audio and CD tapes are still consumed by connoisseurs and musicians alike. Although digital music players and online music applications such as Joox, Spotify, Apple Music or Sky Music is very important in the spread of music in the digital era. The attitude of independent musicians or who are familiar with the term indie musicians still maintains the release of physical music as a tool for the dissemination of their work. This article presents descriptive data from existing journals which are then combined with interviews to obtain depth about what shapes the attitude of indie musicians in using physical music releases and how indie musicians and indie music distributors collaborate in communicating works - indie musicians work through strategies that are done together. As well as what indie music absorbs local culture and how they influence their work and what their attitudes are. Do they not pay attention to the presence of digital distribution or even combine these two things. With the existence of this article, the description of the things that underlie the independent musicians released the music they made themselves with the release of physical albums.
\end{abstract}

Keywords: audio technology, indie music, media disruption, music distribution, physical music

\begin{abstract}
Abstrak
Rilisan musik fisik tidak akan pernah punah, sebagaimana pun teknologi mendisrupsi teknologi audio. Artikel ini memberikan penjelasan tentang rilisan musik fisik pada era digital, dimana piringan hitam (vinyl), kaset audio dan CD masih tetap dikonsumsi oleh para penikmat serta pelaku musik. Walaupun pemutar musik digital dan aplikasi musik secara online seperti Joox, Spotify, Apple Music ataupun Langit Musik sangat berperan penting dalam penyebaran musik di era digital. Sikap dari musisi independen atau yang akrab dengan sebutan musisi indie tetap mempertahankan rilisan musik fisik sebagai alat untuk penyebaran karya mereka. Penelitian ini bertujuan untuk melihat bagaimana rilisan musik fisik akan tetap bertahan, dan mengapa sebuah rilisan fisik menjadi hal yang dianggap penting bagi musisi Indie. Artikel ini menyajikan data-data secara deskriptif dari jurnal-jurnal yang ada yang kemudian di padupadankan dengan wawancara untuk memperoleh kedalaman tentang apa yang membentuk sikap dari para musisi indie dalam menggunakan rilisan musik fisik dan bagaimana musisi indie dan distributor musik indie melakukan kolaborasi dalam mengomunikasikan karya-karya musisi indie melalui strategi yang dikerjakan bersama. Serta seperti apa musik indie menyerap budaya lokal dan bagaimana hal tersebut memberikan pengaruhnya pada karya-karya mereka dan seperti apa sikap mereka. Apakah kehadiran distribusi yang dilakukan secara digital tidak mereka hiraukan atau malah menggabungkan kedua hal tersebut. Adanya artikel ini, memberikan gambaran hal-hal yang mendasari para musisi independen merilis musik yang mereka buat sendiri dengan rilisan album fisik.
\end{abstract}

Kata Kunci: disrupsi media, distribusi musik, musik fisik, musik indie, teknologi audio 


\section{Pendahuluan}

Budaya mengonsumsi rilisan musik fisik tidak akan pernah hilang. Kehadiran aplikasi seperti Spotify, Joox, Apple Music dan Deezer sebagai platform musik saat ini semakin besar, dimana para penggunanya semakin bertambah dari tahun ke tahunnya. Spotify sebagai salah satu pemutar musik digital yang saat ini digemari oleh anak muda dimana aplikasi tersebut memberikan kemudahan untuk para musisi indie dalam menjual karya musiknya karena jangkauan yang cukup luas (Netti \& Irwansyah 2018). Akan tetapi tidak menyurutkan para penikmat musik fisik mengonsumsi musik menggunakan media non aplikasi atau yang dikenal dengan musik fisik seperti Piringan Hitam, Kaset dan Compact Disc (CD).

Adapun tujuan dari Penelitian ini adalah untuk melihat bagaimana rilisan musik fisik akan terus bertahan, dan mengapa sebuah rilisan fisik seperti kaset, cd ataupun piringan hitam menjadi suatu hal yang dianggap penting bagi musisi Independent atau yang sering kali dikenal sebagai musisi indie.

\section{Rilisan Fisik}

Compact Disc atau CD merupakan teknologi terakhir dari bentuk musik fisik yang pernah dikonsumsi oleh para penikmat musik, bentuk fisik CD yang ringan serta portabilitas yang mudah melepaskan musik dari kemasan, anotasi, dan desain yang dimaksudkan untuk memastikan nilai dan integritas CD sebagai bentuk dari budaya yang berbeda (Straw \& Straw, 2015).

Kemunculan CD merupakan sebagai satu format yang menjembatani era analog dengan era digital, pada tahun 1982 CD mulai dibuat dan pada tahun 1983 dibuat secara masal di Jepang yang kemudian merambah ke negara-negara di Eropa (Hopewell, 2012). Keberhasilan CD dalam perkembangan musik fisik, kemudian menggeser keberhasilan piringan hitam, dimana dalam perkembangannya mampu menciptakan rilisan baru di era 1990an (Regan, 2018). Compact disk atau CD memiliki peran penting dimana terjadinya pergeseran dari musik analog ke digital bertransformasi (Regan, 2018)

Dalam industri rekaman, CD bukan menjadi satu-satunya pilihan dalam mengonsumsi musik fisik, akan tetapi ada kaset dan piringan hitam yang saat ini mulai kembali digandrungi oleh para pengoleksi musik-musik lokal. Vinil atau piringan hitam merupakan salah satu bentuk teknologi untuk reproduksi musik fisik yang digunakan hingga akhir abad ke-20. Dimana proses pembuatan musik itu ditorehkan dalam bentuk jalur jarum yang membentuk spiral, yang awal mulainya pada bagian luar rekaman dan pada bagian akhirnya berada di tengahtengah piringan tersebut (Regan, 2018). 


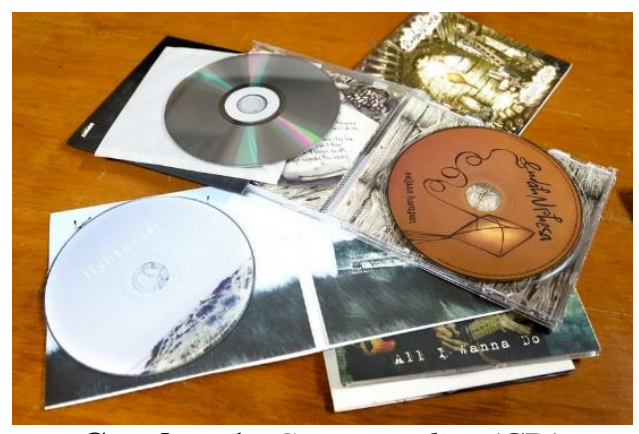

Gambar 1: Compact disc (CD)

Kaset audio merupakan salah satu bentuk rilisan musik fisik, yang dikenal dengan kaset pita. Kaset sendiri berada pada posisi pinggiran koleksi musik, tanpa memiliki sarana yang saat ini nyaman untuk digunakan dalam pengambilan digital konten mereka. Jika dilihat dari Dua puluh tahun yang lalu, industri musik sempat terancam dari kemunculan kaset audio karena kemudahan dari proses penggandaan tanpa izin yang sempat marak dimana-mana yang mengganggu kestabilan dari hak cipta pemilik lagu dan label (industri musik) (Straw \& Straw, 2015).

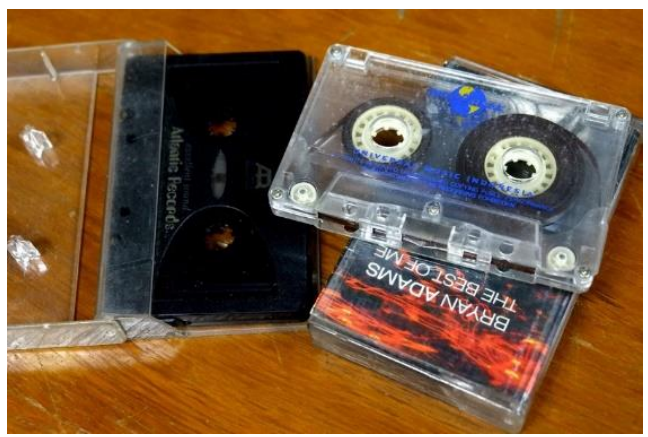

Gambar 2: Kaset audio

Vinyl atau piringan hitam merupakan salah satu bentuk rilisan musik fisik, dimana teknologi ini dominan digunakan untuk reproduksi musik hingga akhir abad ke-20. Cara kerja piringan hitam adalah Musik itu ditorehkan pada bagian spiral pringan hitam tersebut mulai dari bagian luar rekaman dan berakhir di tengah disk (Regan, 2018). Vinyl memberikan kejutan tiap tahunnya karena dengan maraknya vinyl menjadikan kondisi rilisan musik fisik naik dan dapat bertahan pada industrinya dimana dilihat adanya kenaikan konsumsinya pada tahun 2018 kemarin menjadikan pasar musik rilisan fisik dunia naik beberpa persen dari tahun sebelumnya (IFPA, 2019) 


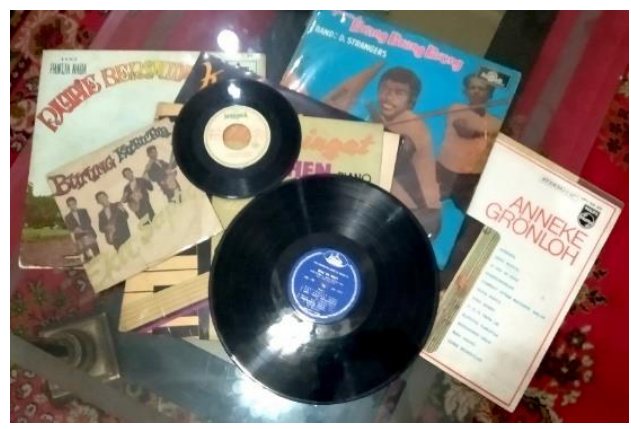

Gambar 3: Vinyl

Berdasarkan laporan dari The IFPI Global Music Report tahun 2018 Pendapatan dari format fisik mengalami penurunan sebesar 5,4\%, pada tahun 2017 ke 2018 (IFPA, 2018) dan dari laporan IFPI tahun 2019 Pendapatan dari format musik fisik terus mengalami penurunan pada tahun 2018, dimana angka yang diperoleh turun sebanyak $10,1 \%$ pada tahun sebelumnya. keadaan pasar, mayoritas mengalami penurunan pendapatan pada sektor format fisik, dimana terdapat sejumlah kecil pasar yang berbeda dari tren lainnya, yang membukukan adanya pertumbuhan pada negara-negara tertentu seperti di India $+21,2 \%$; Jepang $+2,3 \%$; Korea Selatan $+28,8 \%$, dan fisik pendapatan masih merupakan persentase yang signifikan dari pasar di beberapa negara seperti pada pasar di Jepang 71\%, Polandia 47\% dan diikuti oleh Jerman sebesar 35\% (IFPA, 2019).

Pada data tersebut memperlihatkan adanya penurunan terhadap industri musik fisik, akan tetapi pada sektor piringan hitam mulai terlihat peningkatan konsumsi dimana pada tahun 2017 pendapatan global dari piringan hitam atau vinyl berdasarkan data penjualan vinil tumbuh $22,3 \%$ dan merupakan $3,7 \%$ dari jumlah keseluruhan pasar musik yang pada tahun 2017 melakukan produksi rekaman (IFPA, 2018).

Dilihat dari awal mula distribusi musik, sebelum adanya industri rekaman, bahkan jauh sebelum adanya lembar-lembar musik atau yang dikenal dengan music sheet dibuat, cara untuk mendengarkan musik hanya dengan mengalaminya secara langsung, contohnya seperti menonton konser secara langsung jika melihat contoh zaman sekarang atau bisa juga seperti menyaksikan pertunjukan musik jalanan yang disuguhkan oleh para pengamen di jalanan inilah yang disebut dengan Live Performance (Miller, 2012).

Pertunjukkan musik atau live show merupakan ajang bagi para musisi dalam memberikan pengalaman atau experience kepada pendengarnya ataupun kepada orang-orang yang akan menjadi calon pendengarnya. Dari pengalaman yang mereka dapatkan tersebut barulah mereka bisa memutuskan untuk menjadi pendengar yang serius mengikuti musisi atau band yang mereka tonton tersebut. Jadi dapat dikatakan bahwa sebuah pertunjukkan musik merupakan salah satu bentuk komunikasi langsung seorang atau sekelompok musisi kepada pendengarnya.

Bagi musisi Indie tahapan pertunjukkan musik ini menjadi salah satu cara mereka memasarkan rilisan fisik mereka, dari kualitas penampilan yang baik akan cukup memberikan dampak sebuah band. Musik indie memiliki bentuk komunikasi musik yang memiliki aspek psikologis, aspek persepsi dan aspek 
sosial yang saling tumpang tindih (Kjus, 2016). Adanya aspek persepsi pada saat penerimaan suara memberikan nuansa ekspresi yang dirasakan serta aspek psikologis yang memberikan interpretasi musik dimana adanya pera emosi serta ingatan pengalaman terhadap suatu lagu atau music yang menjadi pemicu, pada akhirnya adanya pengalaman yang terbangun secara sosial dengan musisi atau artis melalui sebuah pertunjukkan live show (Hesmondhalgh, 2013; Kjus, 2016).

\section{Musik Indie}

Musik indie berasal dari kata musik independen dimana adanya keinginan untuk mengelurkan idealisme dalam bermusik tanpa melihat pasar dan industri musik seperti apa, namun memberikan suguhan musik yang terbaik dari para musisi indie tersebut, serta adanya inovasi terhadap musik-musik yang disajikan (Wang, 2016). Salah satu yang menjadi ciri dari musik indie adalah musik yang disajikan berbeda dengan selera pasar yang pada umumnya, akan tetapi musik yang disajikan memiliki unsur-unsur yang menarik serta memiliki warnanya sendiri (Kim, 2019).

Fonarow (2006) pada penelitiannya berhasil mengelompokkan definisidefinisi dari musik indie yang seringkali digunakan, adapun musik indie adalah sebagai: (1) jenis produksi musik yang berafiliasi dengan label rekaman independen kecil dengan gaya serta jalur distribusi yang berbeda dengan major label pada umumnya, yang menjadikannya khas label independen; (2) sebuah aliran atau genre dalam musik yang memiliki suara yang khas yang dipadukan dengan gaya tertentu; (3) musik yang mengkomunikasikan bentuk pandangan hidup atau etos tertentu dan menjadi sikap dari musisinya; (4) musik dalam kategori penilaian kritis; dan (5) musik yang dapat dipadupadankan dengan genre lain, seperti pop mainstream, tari, blues, country, atau klasik sehingga menjadi bentuk genre yang baru contohnya seperti terciptanya world musik dimana adanya gabungan unsur musik pop dengan musik tradisonal (Fonarow, 2006).

Musisi indie adalah orang-orang yang membawakan musik indie, dimana musik yang mereka hasilkan terlepas dari kepentingan label-label major dan pendapat pasar. Para musisi indie menciptakan serta membawakan lagu hasil karya mereka sendiri (Turgeon, 2009). Istilah 'indie' tersebut dapat dilihat sebagai istilah untuk para musisi yang mencoba mempertahankan 'aura seni yang asli', dan juga yang mencoba menjaga sikap anti-arus utama dengan memproduksi musik yang menjadi identitas mereka berdasarkan idealisme, akan tetapi tidak menolak untuk mendapatkan paparan media, dimana artis atau musisi tersebut dapat memperoleh publisitas yang lebih luas melalui sarana komersial (Nelson \& Nelson, 2018).

Salah satu yang menjadi ciri dari musik indie juga adalah adanya unsur lokalitas yang mereka bawa sebagai bagian dari identitas mereka, baik itu lagulagu mereka, bahasa serta penggunaan atribut saat melakukan pertunjukkan musik secara langsung. Musik indie begitu erat diidentifikasi dengan keadaan geografis dan juga bentuk fisik tertentu, cara dimana itu dapat dipahami dalam kaitannya dengan identitas lokal adalah hal yang penting. Dimana subjektivitas dan identitas dibentuk, diubah, dan terus terpelihara dalam hal yang dinamakan lokalitas yang terbentuk dari adanya batas-batas geografis, oleh terciptanya jaringan hubungan 
antar manusia sebagai makhluk sosial, oleh rasa sejarah lokal setempat, dan sangat berbeda dengan lokalitas lain (Kruse \& Kruse, 2010). Dari hal tersebut bisa dilihat adanya hubungan antar musisi indie karena adanya kesamaan sebagai band indie.

\section{Musik di Era Digital}

Jika menelusuri musik di era digital, CD merupakan pintu masuk pertama yang menajdikan musik dengan format digital (Regan, 2018), fungsi CD yang bisa menyimpan file audio dan kemudian dapat didengarkan melalui perangkatperangkat yang telah tersedia. Melalui komputer, file yang berbentuk data tersebut bisa diambil dari CD dan dipindahkan ke hard disk yang ada pada komputer.

Musik digital merupakan bentuk dari proses terwakilkannya suara sebagai nilai biner numerik ( 0 dan 1), dimana paradigma sebelumnya sangatlah berbeda, dikarenakan pada media analog seperti piringan hitam atau pita magnetik digunakan untuk mewakili dan menyimpan suara di sini terdapat peran dari bahan-bahan kimia sebagai sumber penyimpanan suara tersebut (Regan, 2018).

Konsumsi musik secara besar-besaran terjadi di era sekarang, musik dapat ditemukan dimana-mana, kehadiran aplikasi musik seperti Apple music, Spotify, Joox ataupun Melon pada telepon pintar mulai mendominasi pendistribusian musik secara digital (Arditi, 2017). Penggunaan aplikasi tersebut memberikan kemudahan mengakses banyak kumpulan lagu-lagu lainnya dari berbagai macam musik hingga ke podcast.

Pentingnya untuk memahami bagaimana teknologi berubah, serta terjadinya proses digitalisasi memberikan pengaruh terhadap industri musik secara menyeluruh merupakan hal yang penting, terlebih untuk melihat seberapa besar pengaruhnya terhadap kesejahteraan. Untuk mempromosikan sebuah inovasi serta dapat memaksimalkannya untuk mencapai kesejahteraan, serta adanya perlindungan terhadap hak cipta memperdagangkan biaya yang dapat membatasi akses ke karya kreatif (contohnya: Lagu, Drama Audio) dengan manfaat dari memberikan insentif untuk membuatnya (Aguiar \& Martens, 2016).

Dari hasil riset yang dibuat oleh daily social pada tahun 2018 lalu diketahui bahwa teknologi membuat orang mengonsumsi musik secara online sebesar $88 \%$ dimana angka tersebut hampir merambah ke $90 \%$, yang artinya konsumsi musik digital di Indonesia sudah cukup besar untuk mereka yang memiliki telepon pintar dengan tingkat mendengarkan musik secara online selama 1-14 jam setiap minggunya (DailySocial.id, 2018).

\section{Merilis Musik Fisik sebagai Suatu Sikap}

Di awal tahun 2018 yang lalu, label musik raksasa yang sering disebut dengan Major Label yang berada di Indonesia (Sony, Warner, EMI, Universal Music Group dan Musica Studio) mulai berhenti mengeluarkan rilisan musik fisik. Hal ini dikarenakan konsumsi para penikmat musik di Indonesia mulai beralir ke digital, namun bukan berarti mereka bener-benar beralih ke digital akan tetapi lebih berfokus pada rilisan digital walaupun masih terdapat beberapa rilisan fisik yang bekerja sama dengan salah satu gerai ayam milik KFC. 
Riomanadona M Putra, Irwansya: Musik Rilisan Fisik Di Era Digital: Musik Indie Dan Konsumsi Rilisan Musik Fisik

Di lain sisi dari Major Label, Indie label seperti DeMajors ataupun Kolibri Records tetap mengeluarkan rilisan fisik dari band-band yang bernaung di bawah mereka. Dari data yang diperoleh secara global dari pendapatan sektor digital terjadi pertumbuhan sebesar $21,1 \%$ menjadi US \$ 11,2 miliar di tahun 2018, melampaui angka US \$ 10 miliar untuk pertama kalinya dan sekarang merupakan $58,9 \%$ dari total pendapatan musik yang direkam, sedangkan pada rilisan musik fisik turun sebesar 10,1\% dari tahun sebelumnya (IFPA, 2019).

Angka-angka tersebut tidaklah terlalu dilihat oleh kebanyakan musisi yang berada di jalur side-stream (musisi indie). Sebut saja musisi-musisi seperti Endah dan Rhesa, Tulus, Mocca, Barasuara dan Elephant Kind tetap merilis karya-karya mereka dalam bentuk CD bahkan ada beberapa musisi Indonesia mengeluarkan Kaset audio dalam jumlah yang terbatas. Tidak hanyak terbatas pada musik fisik saja, dalam wawancara dengan pemilik dari De Majors, David Karto mengatakan bahwa De Majors akan selalu membantu para musisi indie untuk mengeluarkan rilisan-rilisan fisik yang juga dibarengi dengan strategi secara digital.

Adanya kesamaan pandangan musisi ndie tentang rilis musik fisik sebagai salah satu pencapaian, dimana hasil suara yang didengarkan akan lebih baik jika menggunakan pita kaset audio, bukan dengan menggunakan perlatan digital, ada perasaan yang cukup dalam ketika merekam sebuah karya dengan menggunakan media seperti kaset audio, yang menurut para musisi tersebut lebih nikmat. Adapun treatment yang dilakukan oleh Syahrani Queen fire works ketika melakukan sesi rekaman adalah memanusiakan sebuah karya, dengan merekam seperti gaya merekam pada zaman pita kaset, yang jika melakukan kesalahan baik saat bernyanyi atau mengisi musik hanya diperbolehkan empat kali saja, demi mendapatkan perlakuan audio yang khas dengan pita kaset dan membuat si musisi dapat berlatih mengasah kemampuannya agar dapat bermain musik dengan lebih baik lagi. Hal serupa juga diungkapkan oleh Kjus dalam penelitiannya, bahwa dengan masuknya album ke dalam trek bentuk digital individual dan juga lagu rilisan single hits yang disebarkan dapat memicu ketidakpastian mengenai ekspresi kreatif seniman yang mengancam kedalaman tampilan psikologis dari niat mereka (Kjus, 2016).

Sejalan dengan yang dilakukan oleh band Efek Rumah Kaca pada saat merekam karya mereka di studio Lokananta yang berada di kota Solo. Lokananta merupakan studio bersejarah Indonesia yang menggunakan peralatan analog untuk merekam karya-karya para musisinya. Dari hal tersebut dapat diambil sebuah kesimpulan bahwa musisi indie memiliki sikap yang cukup idealis dalam membuat sebuah karya. Salah satunya adalah sikap mempertahankan rilisan fisik. Teori sikap tersebut yang diungkapkan oleh La Pierre mengenai Attitude Theory, dimana dalam sebuah situasi sosial yang cukup sederhana sikap ditandai sebagai suatu pola prilaku, kemudian kesiapan antisipatif serta adanya predisposisi dimana adanya seperti yang diungkapkan sebelumnya untuk bersosialisasi. Sikap merupakan bentuk dari respon pada stimuli sosial yang dapat dikondisikan (La Pierre, 1934).

Contoh dari sikap yang dimaksudkan oleh La Pierre merupakan teori psikologi, jika diberikan contohnya adalah pada musisi Indie yang memiliki kecendrungan untuk membuat sebuah rilisan fisik sebagai salah satu bentuk 
penghargaan akan karya mereka sendiri, hal inilah yang ditularkan kepada bandband indie lainnya, sebagai salah satu sikap yang mencerminkan band indie dalam berkarya. Bahwa rilisan fisik memiliki tempat yang lebih tinggi dibandingkan dengan rilisan digital. Sejalan dengan yang diucapkan oleh David Karto bahwasannya setiap band independent yang mengeluarkan rilisan fisik, selalu mempersiapkannya dari jauh hari, karena album fisik itu seperti menanti kelahiran anak maka diperlukan perhatian yang lebih terhadap sebuah karya fisik.

\section{Metode Penelitian}

Metode yang digunakan pada penelitian ini adalah pendekatan kualitatif deskriptif, yaitu pendekatan kualitatif yang memberikan gambaran keadaan rilisan musik fisik pada musik indie dilihat dari sikap musisi indie terhadap rilisan musik fisik yang digabungkan dengan wawancara oleh narasumber pemilik Indie Label.

Metodologi deskriptif memiliki tujuan untuk mendapatkan cerita, dan memperoleh perspektif orang yang berbeda-beda berdasarkan pengalaman mereka yang berbeda pula (Patton, 2014). Sedangkan menurut Whitney (1960) metode deskriptif merupakan metode yang mencari fakta dengan menggunakan interpretasi jelas serta tepat. Pada penelitian ini menggunakan tinjauan pustaka berdasarkan jurnal-jurnal yang sudah ada pada penelitian sebelumnya, kemudian digabung dengan menggunakan teknik wawancara dengan seorang narasumber untuk melengkapi data-data. Data yang diperoleh dari wawancara tersebut tidak hanya sebatas mendapatkan data untuk menganalisa kata-kata dari hasil wawancara saja, tetapi memungkinkan orang yang diwawancarai untuk "berbicara dengan suara mereka sendiri dan mengekspresikan pikiran dan perasaan mereka sendiri" (Berg, 2007; Alshenqeeti, 2015). Wawancara yang dilakukan dalam penelitian kualitatfif dapat dilakukan dimanapun lingkungannya dimana jenis wawancara lainnya sedang berlangsung (Patton, 2014)

Penggunaan metode kualitatif yang dilakukan secara deskriptif haruslah secara menyeluruh tanpa membuat peneliti menjadi kurang peduli, atas hal-hal yang dianggap kecil dan sangat sepele yang tentu saja kurang relevan. Kriteria dasar yang sangat baik untuk diterapkan pada penelitian deskriptif adalah sejauh mana pengamatan tersebut dapat memungkinkan pembaca dari jurnal ini dapat masuk dan dapat pula memahami situasi yang terjadi tersebut diteliti (Patton, 2014). Deskriptif dapat membawa pembaca kedalam bentuk pengaturan dimana terdapat data-data yang tidak bersifat penilaian seperti baik atau burukm sesuai atau tidak sesuai, berguna atau tidak berguna, data akan bersifat untuk menggabarkan apa yang terjadi (Patton, 2014).

\section{Hasil Penemuan dan Diskusi}

\section{Kelompok dalam Musik Indie}

Tak bisa lepas dari budaya lokal, dalam setiap musisi independen atau musisi indie, peran dari budaya lokal menjadi salah satu ciri yang melekat pada masing-masing personalnya. Oleh karena adanya budaya yang melekat otomatis ada bentuk kelompok-kelompok yang terbentuk secara tidak langsung yang 
Riomanadona M Putra, Irwansya: Musik Rilisan Fisik Di Era Digital: Musik Indie Dan Konsumsi Rilisan Musik Fisik

memberikan pemahaman serta pengalaman mereka dalam membentuk apa yang disebut dengan musik indie. Musik indie memiliki kaitan yang erat dengan terbentuknya identitas dengan ruang geografis dan fisik tertentu, cara dimana itu dipahami dalam kaitannya dengan identitas lokal adalah penting (Kruse \& Kruse, 2010).

Kelompok atau komunitas indie awalnya muncul sebagai bentuk perlawanan atas pengekangan kreativitas oleh industri musik raksasa (arus utama). Kemunculan musik indie berasal dari jaringan organisasi pasca-punk yang muncul dalam bentuk yang lebih kongkrit dan jelas. Dimana mereka menemukan Halangan dalam bentuk tantangan yang lebih bersifat komersial dimana budaya komersil tersebut merupakan hal yang sangat disukai oleh perusahaan rekaman raksasa (Hesmondhalgh, 2013). Jika dilihat, sejarah perjalanan musik indie, adanya obsesi musik indie terhadap temuan baru adalah reaksioner, mengelak dari yang popular atau dikenal banyak orang serta, jarang memberikan posisi para pendengar dan musisi dalam lingkup komersial industri musik atau lebih tepatnya menjadikan hal tersebut sebagai komoditas komersial (Rogers \& Rogers, 2010).

Kelompok memiliki peran sentral dalam musik indie dan juga merupakan tempat bagi para pelaku musik indie untuk memperdengarkan karya-karya mereka. Beberapa komunitas ataupun label independen berpartisipasi dalam membentuk pemahaman mengenai musik indie itu sendiri. Dalam wawancara dengan David Karto, Salah satu pendiri dari DeMajors, salah satu label independen yang konsisten dengan rilisan fisiknya mengungkapkan:

"DeMajors memposisikan diri sebagai penyuka music-musik cutting edge atau musik DIY, yang memiliki ekspresi yang berbeda, sudut pandang berebeda, proses kreatif mereka yang masih berada dalam ruang idealis mereka, kalau kita sebut bisa berekspresi lebih luas."

Dari adanya kesamaan tentang kebebasan dalam mengekspresikan musik tersebutlah terbentuknya kelompok-kelompok atau komunitas-komunitas musik. Beberapa di antaranya mengadakan gigs atau pertunjukan live music yang bertujuan memperkenalkan karya-karya milik mereka sendiri ataupun. Gigs menjadi ajang memamerkan musik idealis mereka kepada para musisi indie lainnya dan calon pendengar mereka (Harvey, 2017; Rogers \& Rogers, 2010). Tidak hanya soal pertunjukkan, rilisan musik fisik pun menjadi bahasan penting setiap musisi yang hadir pada pertunjukkan tersebut.

\section{Rilisan Musik Fisik Sebagai Identitas}

Hesmondhalgh (2013) mengungkapkan bahwa kemunculan musik indie pada akhir tahun 1980an sebagai bentuk perlawanan terhadap industri musik raksasa. Pada tahun 1988-1992 terjadi resesi ekonomi yang membuat jaringan musik independen sebagai genre masuk ke ceruk pasar. Beberapa band bintang muncul untuk mewarisi The Smiths, New Order dan sejenisnya. Dimana Ada anggapan bahwa warisan punk telah berjalan dengan sendirinya (Hesmondhalgh, 2013). Musik indie merupakan merupakan salah satu nieche market yang sampai saat ini masih terus seperti itu. 
Musik indie sebagai nieche market bukanlah salah satu bentuk kegagalan, pada zaman dimana rilisan musik fisik, seperti kaset dan cd masih merajai pasar musik, musik indie tetap menunjukkan taringnya dengan membuat acara-acara live show atau gigs-gigs kecil dimana itu menjadi identitas mereka akan tetapi para musisi indie pada saat itu juga menggunakan rilisan musik fisik yang mereka buat seadanya untuk dikonsumsi oleh para fans mereka. Saat ini ketika musik digital menjadi raja di industri musik, rilisan musik fisik, seperti vinyl, kaset dan CD menjadi identitas musik indie. Seperti yang diungkapkan oleh David Karto:

"Terus kenapa kita masih tetap membuat rilisan fisik, itu merupakan komitmen kita, artinya si CD, si Vinyl, si Kaset masih menjadi ruang, menjadi gerbong yang artinya identitas dalam sebuah industri musik."

Harvey (2017) dalam temuannya melihat anak muda akan mengkomsumsi vinyl ketika adanya preferensi dari para pemakai vinyl sebelumnya. Dari sinilah banyak anak muda yang ikut mengkonsumsi vinyl sehingga membuat rilisan musik fisik vinyl menjadi digemari. terutama di antara konsumen musik yang masih muda - hal ini yang kemudian menunjukkan, adanya ideologi media yang bisa meluas ke sifat material sebuah media. Adapun penyebarannya dengan cara yang menyenangkan, dimana totebag souvenir dari acara Record Store Day memberikan kejelasan terhadap rangkaian dari ideologi media tentang harga unik dari bentuk rilisan musik fisik terutama pada rekaman vinyl, secara khususnya pada aspek yang berkaitan dengan 'tangibilitas' mereka. Pada totebag yang didapat dari acara Record Store Day, media rekaman vinyl yang 'kronologis' terjadi penggantian nama agar dapat menyoroti harga dari bahan-bahan inti dari rilisan musik fisik, yang memiliki tujuan wacana utama penyampaian pesan lewat visual totebag dengan penyampaian kepada anak-anak muda penggemar musik yang saat ini sangat didominasi oleh format digital dan aplikasi (Harvey, 2017).

Dalam Teori Attitude yang diungkapkan oleh Fishben \& Ajzen (1975), bahwa sikap atau attitude dipengaruhi oleh tiga hal yaitu Belief (diri sendiri), Norma (kelompok) dan PBC (Instansi/organisasi resmi) dari Sikap/attitude menjadi intensi yang kemudian menjadi perilaku (Fishbain \& Ajzen, 1975). Maka untuk sesorang yang bisa mengatakan dirinya bagian dari musik indie atau independen adalah yakin terhadap diri sendirinya adalah musisi independen dan kemudian secara kelompok juga diakui, bahwa dia adalah musisi indie dan pada akhirnya secara resmi memiliki karya yang diakui secara resmi, seperti memiliki karya yang telah dirilis dan disebarkan. Attitude dari musisi indie yang konsisten dengan rilisan musik fisik. Karena adanya kebanggaan bagi musisi indie dalam merilis sebuah karya yang berbentuk fisik. Bahwa musisi memiliki kebanggaan tersendiri ketika mengeluarkan rilisan musik fisik sebagaimana yang disampaikan oleh David Karto:

"Pada saat lu punya anak seperti lu punya CD. Pada saat mau punya anak preperationnya pun semua sudah dipikirkan, pada saat anak ini brojol anak lu juga lu uruskan, ya lu jagain ke dokter dan segala macam. Dan sama aja ketika lu proses punya CD semua band harus menjaga bagaimana proses CD tersebut bisa berjalan" 
Dari teori tersebut juga dapat berkembang ke teori kelompok terpercaya milik Bales (Littlejohn \& Foss, 2008), adapun dua macam karakteristik teori kelompok terpercaya, yang pertama adalah dimana adanya ketergantungan terhadap lingkungan mereka yaitu komunitas sesama musisi indie dan berikutnya merupakan adanya batasan yang dapat ditembus, ini dapat dilihat dari apa yang dibuat para musisi indie dalam mengerjakan sebuah rilisan fisik. Seperti bagaimana pengaruh dari kelompok musisi indie pada sebuah band yang akan merilis karyanya, dan bagaimana band tersebut menghargai karyanya apakah sebatas rilis secara digital ataukah rilis secara fisik atau menggabungkan dua hal tersebut.

\section{Simpulan}

Rilisan musik fisik tidak akan hilang seiring dengan perkembangan musik digital, akan tetapi rilisan fisik menjadi identitas musisi indie dalam bermusik. Sikap yang dimiliki oleh musisi indie menunjukkan bahwa identitas yang mereka perlihatkan tersebut tercermin dari bagaimana mereka memperlakukan karyakarya mereka terutama pada rilisan musik fisik. Musisi indie tidak menolak digital dan tidak sepenuhnya setuju dengan rilisan musik fisik. Akan tetapi bagaimana mereka dapat mengombinasikan rilisan musik fisik dan digital yang nantinya menjadi strategi masing-masing musisi dalam berpromosi.

Dari data yang diperoleh dari tahun 2018 dan 2019 terlihat kenaikan angka musik yang membuat rilisan musik secara digital dibandingkan dengan fisik dan di tahun 2019 ini angka tersebut naik sebanyak 11\% mengonsumsi musik secara digital (IFPA, 2019). Akan tetapi pada musik rilisan fisik juga ada kenaikan angka untuk sektor piringan hitam (vinyl) dimana pada 2018 angka tersebut sempat naik di angka 30\% (IFPA, 2018)

Musisi indie dalam melakukan rilisan musik fisik pada hakikatnya terpengaruh oleh kelompok musisi indie lainnya dalam berpikir tentang rilisan musik fisik, bagaimana kebanggaan sebagai musisi Indie dalam menelurkan karya dalam bentuk fisik yang dikatakan oleh David karto pada wawancaranya bahwa perlakuan terhadap musik fisik dan digital itu berbeda. Pada musik fisik sangat diperlukan biaya-biaya yang lebih agar karyanya dapat tersebar, dimana hal tersebut sangat berbeda dengan rilisan musik digital yang tidak terlalu mengeluarkan banyak biaya untuk proses produksi dan distribusinya.

\section{Ucapan Terima Kasih}

Penulis mengucapkan terima kasih yang sebesar-besarnya kepada Dr. Irwansyah, MA karena telah memberikan dukungan kepada Riset tentang musik fisik di era digital ini berdasarkan referensi serta arahan-arahan tentang perkembangan di industri teknologi komunikasi dan untuk keilmuan di jenjang Magister Manajemen Komunikasi Fakultas Ilmu Sosial Ilmu Politik Universitas Indonesia. 


\section{Daftar Pustaka}

Aguiar, L., \& Martens, B. (2016). Digital music consumption on the Internet: Evidence from clickstream data R. Information Economics and Policy, 34:27-43. https://doi.org/10.1016/j.infoecopol.2016.01.003. [24/03/2019].

Alshenqeeti, H. (2015). Interviewing as a Data Collection Method: A Critical Review Inter-viewing as a Data Collection Method: A Critical Review, (August). https://doi.org/10.5430/elr.v3n1p39. [24/05/2019].

Arditi, D. (2017). Music Everywhere: Setting a Digital Music Trap. Critical Sociology, 089692051772919. https://doi.org/10.1177/0896920517729192. [08/02/2019].

Berg, B. L. (2007). Qualitative research methods for the social sciences. London: Pearson.

DailySocial.id. (2018). Online Music Streaming Survey 2018. Jakarta (Indonesia): DailySocial.id. [24/03/2019]

Fishbain, M., \& Ajzen, I. (1975). Belief Attitude Intention and Behavior - An Introduction to Theory and Research.. Philippines: Addison-Wesley.

Fonarow, W. (2006). Empire of Dirt: The Aesthetics and Rituals of British Indie Music. Connecticut: Wesleyan.

Harvey, E. (2017). Siding with vinyl : Record Store Day and the branding of independent music, International Journal of Cultural Studies.20(6):585602. https://doi.org/10.1177/1367877915582105. [03/01/2019].

Hesmondhalgh, D. (2013). Indie: The Institutional Politics and Aesthetics of A Popular Music Genre, 2386. https://doi.org/10.1080/095023899335365. [26/05/2019].

Hopewell, L (2012). The History of The Compact Disc. Gismodo.com. Diakses melalui: https://www.gizmodo.com.au/2012/08/thehistory-of-the-compactdisc/amp. [22/05/2019].

International Federation of the Phonographic Industry [IFPI]. (2018). IFPI Global Music Report 2018. London (UK): IFPI. (2019). IFPI Global Music $\begin{array}{llll}\text { Report 2019. https://doi.org/10.1080/10920277.2000 } & .10595929\end{array}$ [20/05/2019].

Kim, S. (2019). Now it's indie: The creative turn of the cultural policy in the Korean indie music scene. https://doi.org/10.1177/1748048518802965. [22/05/2019].

Kjus, Y. (2016). Reclaiming the music: The power of local and physical music distribution in the age of global online services. https://doi.org/10.1177/1461444815580414. [19/05/2019]

Kruse, H., \& Kruse, H. (2010). Local Identity and Independent Music Scenes , Online and Off Local Identity and Independent Music Scenes, Online and Off, 7766. https://doi.org/10. 1080/03007760903302145. [19/05.2019].

La Pierre, R. T. (1934). Attitudes Versus Actions. Social Forces

Littlejohn \& Foss.(2008) Theories of Human Communication $9^{\text {th }}$ edition. Shenton Way (SG): Cengage learning

Miller, M. (2012). The Ultimate Digital Music Guide The Best Way to Store, Organize, and Play Digital Music. Retrieved from 
http://ir.obihiro.ac.jp/dspace/handle/10322/3933

Nelson, E. H., \& Nelson, E. H. (2018). From selling out to savvy strategy: How the O. C. helped change the stigma around licensing indie music change the stigma around licensing indie music, 0694. https://doi.org/10.1080/17510694.2017.1419051. [22/05/2019]..

Netti, S.Y.M., \& Irwansyah. (2018). Spotify: Aplikasi Music Streaming untuk Generasi Milenial. Jurnal Komunikasi UNTAR (Vol.10, No.1, Juli 2018). Journal.untar.ac.id.

Diakses

dari: http://journal.untar.ac.id/index.php/komunikasi/article/view/1102 [22/05/2019].

Patton, M.Q. (2014). Qualitative Research \& Evaluation Methods $4^{\text {th }}$ Edition. California (US): Sage

Regan, G. O. (2018). The Innovation in Computing Companion. Cham (SW): Springer).

Rogers, I., \& Rogers, I. (2010). You 've got to go to gigs to get gigs: Indie musicians, eclecticism and the Brisbane scene and the Brisbane scene, 4312. https://doi.org/10.1080/10304310802311618. [19/05/2019].

Straw, W., \& Straw, W. (2015). The Music CD and Its Ends In, Memoriam The $\begin{array}{lllll}\text { Music } \quad C D & \text { and Its }\end{array}$ https://doi.org/10.2752/175470709787375751. [19/05/2019].

Turgeon, R. (2009). Indie Rock 101: Running, Recording, and Promoting your Band. Oxford (UK): Focal Press.

Wang, S. (2016). Music, social media and public pedagogy: Indie music in the post-Cantopop epoch. https://doi.org/10.1108/AEDS-03-2017-0022. [22/05/2019].

Whitney, F.L. (1960). The Elements of Research Asian Eds.Osaka (JP): Overseas Book 